Maxillary fractures in children are uncommon

- There is little information regarding the fate of developing teeth in the line of maxillary

fractures.

- This report describes such a case and the subsequent failure of eruption.

\title{
Lack of tooth eruption following maxillary fracture: Case report
}

\author{
F. R. Jenkins ${ }^{1}$, K. Mizen² and R. A. Loukota ${ }^{3}$
}

Aberrant tooth development following facial fractures is unusual. It is commonly reported that tooth buds involved in the line of a mandibular fracture will continue to develop normally and erupt sequentially. Few cases have been cited regarding developing teeth in the line of maxillary fractures. In the case reported, the normal growth and position of a maxillary third molar can be seen to be retarded at the position of a maxillary fracture, sustained by a child in the mixed dentition phase of dental development.

Facial fractures in children are not uncommon, reported as ranging from $8 \%$ to $30 \%$ of recorded maxillofacial injuries. They are generally 1.5 to 2 times more common in boys than girls, the majority being due to assault, road traffic accidents and falls. ${ }^{1}$ Mandibular fractures are more common, accounting for around $69 \%$ of facial fractures in children, maxillary and zygomatic complex fractures account for only $6-7 \% .{ }^{1,2}$ Teeth developing in the line of fracture of the juvenile mandible generally show little disturbance in eruption. It has been reported that one third of mandibular fractures in children involve unerupted teeth. Provided that treatment of the fracture has been conservative, or plates positioned away from the tooth buds. Eightytwo per cent of teeth involved in the fracture site will erupt normally. The remaining 18\% exhibiting delayed eruption, non-eruption or resorption. ${ }^{3}$ There is little data concerning the fate of maxillary

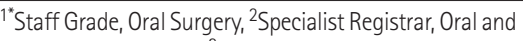
Maxillo-facial Surgery, ${ }^{3}$ Consultant, Oral and Maxillo-facial Surgery, Leeds Dental Institute, Clarendon Way, Leeds LS2 9LU ${ }^{*}$ Correspondence to: Dr F. R. Jenkins, Leeds Dental Institute, Clarendon Way, Leeds LS2 9LU

E-mail: fionajenkins.thedentist@virgin.net

\section{Refereed Paper}

doi:10.1038/sj.bdj.4810822

Received 13.03.03; Accepted 14.05.03

๑ British Dental Journal 2003; 195: 691-692 tooth buds in fracture sites. This is unsurprising, considering the relative incidence of maxillary fractures in children.

\section{CASE REPORT}

A previously fit and well 11-year-old boy was admitted to hospital, following a fall of some 30-35 feet onto a concrete floor, where he was found conscious and crying. He had been playing on the roof of a disused factory and had fallen through a skylight. He was admitted to hospital for neurological observation and treatment of his injuries. He was found to have facial injuries, abrasions on his abdomen and a fractured right ulna. Radiographic examination demonstrated a minimally displaced fracture of the left infra-orbital rim. His other injuries were treated at the time of admission.

Due to bony displacement at the infraorbital fracture site, open reduction and internal fixation was indicated. ${ }^{5}$ This was carried out 9 days after the incident, under general anaesthesia. Access was via an infra orbital, second crease incision, the fracture was reduced and fixed with a six-hole plate and five screws along the left infra-orbital rim. ${ }^{2}$ The bony edges were smoothed, as it has been noted that fractures of the juvenile skull must be reduced exactly. There will be no 'smoothing of edges' during the later growth period. ${ }^{4}$ 


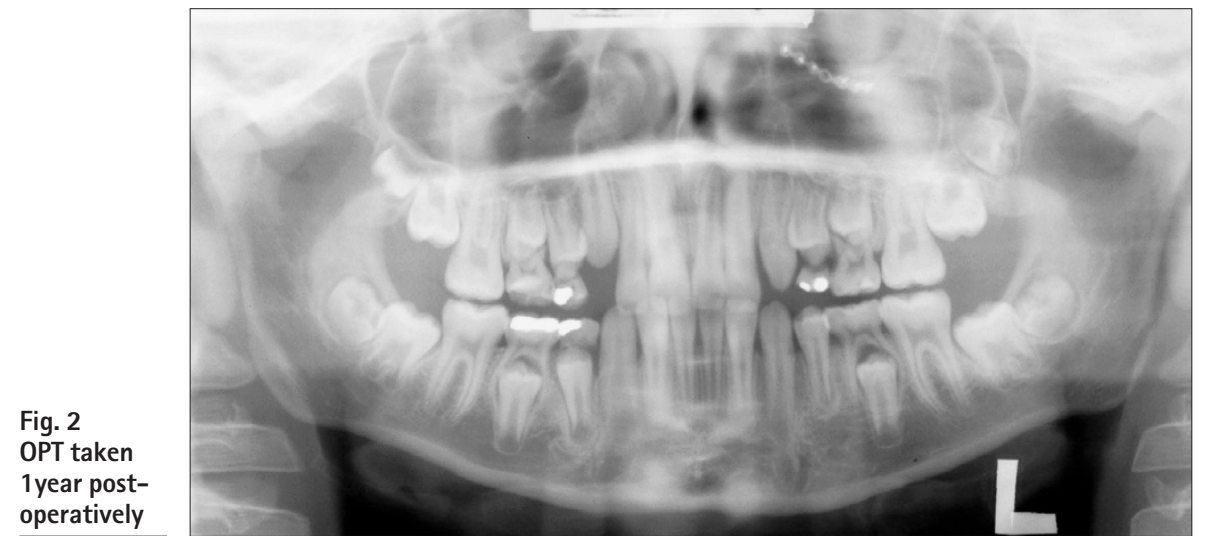

He has been reviewed regularly over the past 5 years to assess his facial growth and any possibility of facial asymmetry brought about by impeded growth in the left maxilla. Mid-facial injuries are felt to be more sensitive to alterations of facial growth, ${ }^{5}$ although long-term effects remain largely undetermined. ${ }^{2}$ Fortunately his facial growth has been unimpeded and symmetrical.

Sequential radiographs have revealed an increasingly aberrant position of the developing UL8 (28). A radiograph taken post operatively (Fig. 1) shows UL8 (28) developing in a relatively 'normal' position, distally and superiorly to UL7 (27).

The radiograph 1 year later (Fig. 2) shows UL8 (28) to have continued developing normally but in a relatively more superior position to UR8 (18).

Five years after the incident and the open reduction and internal fixation of the left infra-orbital rim. The radiograph (Fig. 3) shows UR8 (18) to be well positioned for potential future eruption. UL8 (28), however, is now in an aberrant position, relatively superior and distally orientated.

\section{DISCUSSION}

It has been recorded that developing teeth may appear in aberrant positions for many reasons. Due to idiopathic migration, traumatic displacement of the developing tooth bud (commonly upper incisors due to traumatic intrusion of deciduous incisors), space occupying pathology, eg cysts. The teeth most com- monly found in aberrant position are third molars, mandibular premolars and maxillary canines. ${ }^{6}$ In this case there was no detectable pathology. It does not appear to have been due to direct traumatic displacement of the tooth bud, as this would have been more immediately obvious on the radiograph. It could be idiopathic, third molars being the most commonly impacted teeth. However, we feel that it is more than coincidental that development appeared normal immediately post-operatively and became increasingly abnormal.

Fractures of the zygomatic complex, are as the term implies, are not usually a single entity. They are often referred to as tripod fractures, combining concurrent fracture of the infra-orbital rim, zygomatic arch and the body of the maxilla.

We postulate that the fracture line, though not detectable on the radiographs shown, passed through the maxilla between the developing UL7 (27) and UL8 (28). As growth has continued, the UL8 (28) has continued to develop normally within its follicle, but has been unable to erupt through or beyond the fracture site. It would appear that UL8 (28) has remained in the position it was occupying at the time of fracture. Maxillary growth follows a downward and forward path in relation to the cranial base, although maxillary growth is known to be more complex than this. ${ }^{7-9}$ Thus UL8 (28) has appeared to move superiorly and distally relative to surrounding structures and failed to erupt, whereas on the unaffected side UR8 (18) appears to be erupting normally.

Failure of eruption can be due to many causes, systemic, including endocrinopathies, nutritional deficiencies and chromosome abnormalities; and local causes including idiopathic migration, traumatic displacement or abnormally large crowns. ${ }^{6}$ As previously mentioned, the subject in this case was generally fit and well and the tooth would appear to be of normal size and form. Bone heals initially by callus formation, which over time remodels into normal cortical and cancellous bone. Perhaps, because of the local remodelling of the bone, the tooth in question was deprived of the appropriate balance of biochemical messengers required to initiate tooth eruption at the crucial point in its development.

The UL8 (28) nonetheless remains unerupted. Because of the very low incidence of maxillary fractures in the juvenile dentition and hence the minimal body of evidence, one implication that could be drawn from this case is that teeth in the line of maxillary fractures may remain ectopically positioned.

1. Bamjee $Y$, Lownie J F, Cleaton-Jones P E, Lownie M Maxillo-facial injuries in a group of South Africans under 18 years of age. Br J Oral Maxillofac Surg 1996; 34: 298-302.

2. Posnick J C, Wells M, Pron G E. Paediatric facia fractures: evolving patterns of treatment. J Oral Maxillofac Surg 1993; 51: 836-844.

3. Koenig W R, Olsson A B, Pensler J M. The fate of developing teeth in facial trauma: tooth buds in the line of mandibular fractures in children. Ann Plast Surg 1994; 32: 503-505.

4 Kromminga R, Hemprich A. Midfacial and mandibular body fractures in children and adolescents. Deutsch ZahnartzIZ1990; 45: 812-814.

5 Koltai PJ, Rabkin B, Hoehn J. Rigid fixation of facial fractures in children. J Craniomaxillofac Trauma 1995; $1: 32-42$

6 Soames and Southam. Oral Pathology. 2nd ed. pp3738. Oxford: Oxford University Press, 1988.

7 Bjork $A$. The use of metallic implants in the study of facial growth in children: method and application. Am J Phys Anthropo/ 1968; 29: 243-254

8 Bjork A, Skieller V. Facial development and tooth eruption. An implant study at the age of puberty. $A m J$ Orthod 1972; 62: 339-383.

9 Baumrind S, Korn E L, Ben-Bassat Y, West E E. Quantitation of maxillary remodelling. 1. A description of osseus changes relative to superimposition on metallic implants. Am J Orthod Dentofac Orthop 1987; 91: 29-41.
Fig. 3 OPT taken 5 years postoperatively

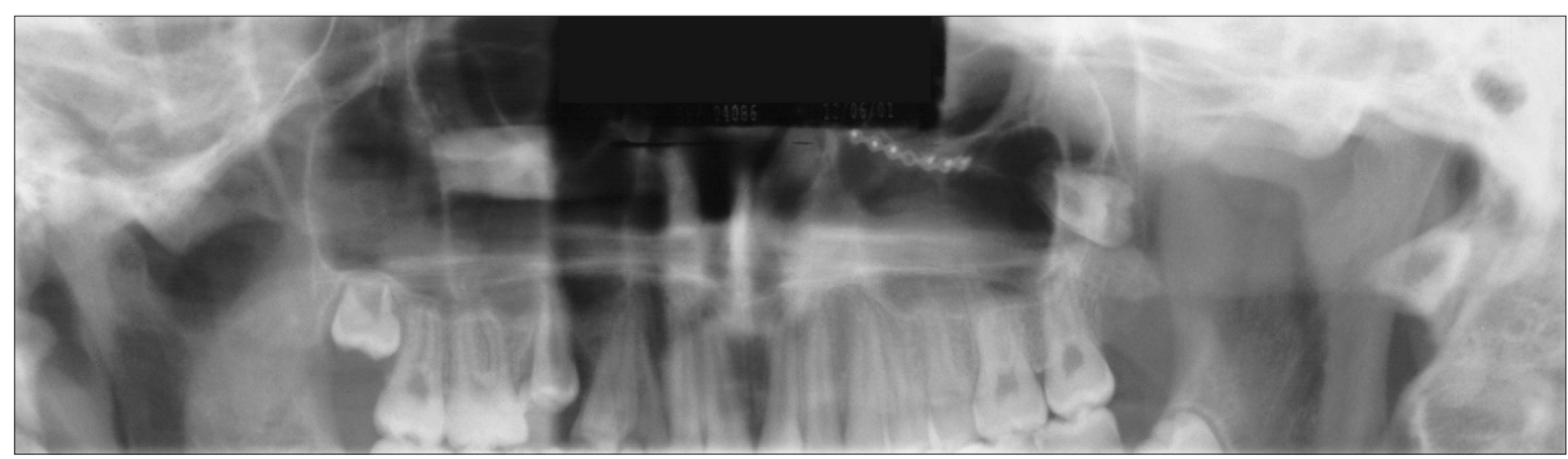

